\title{
STATE AND TRENDS OF THE DEVELOPMENT OF BIOECONOMIC-ORIENTED LIVELIHOOD PRACTICES
}

\author{
B. Stoykova, Y. Yarkova, N. Markov* \\ Department of Regional Development, Faculty of Economics, Trakia University, \\ Stara Zagora, Bulgaria
}

\begin{abstract}
The aim of the present study is to establish the extent to which natural resources are used and how traditional livelihood practices are exercised at a regional level. The object of this study is a region with developed mass tourism - Bansko Municipality. The subject addresses traditional livelihood practices and the opportunities for expanding alternative forms of tourism.

The revival of traditional livelihood models, which directly corresponds to current trends in bioeconomy, can make alternative forms of tourism an important part of the local development strategies in the forthcoming programming period after 2020, including regions established as mass tourism ones. The study has been conducted by applying the survey method in the municipality of Bansko in the period of February-March 2020 coinciding with the onset of the epidemic situation related to COVID-19 in Bulgaria. Taking into account the results from the survey, it is possible to draw conclusions about the extent to which certain conditions for the development of alternative forms of tourism have been created when facing new challenges.
\end{abstract}

Key words: natural resources, bioeconomy, livelihoods, alternative tourism, Bansko Municipality.

\section{INTRODUCTION}

\section{Old livelihood practices}

In the past, Bulgarian society was organized in such a way that it sustained the livelihood of all its members, guaranteeing the respective social status depending on the type of work.

Depending on natural resources, the environment and the degree of development of the respective society, different livelihood practices were formed, some of which declined in the course of the country's historical development, while others remained sustainable and adapted to survive in different forms to the present day.

The traditional Bulgarian agriculture was the main livelihood of the people living in the plains, yet it was found, albeit in a primitive form, in the mountainous regions of Stara Planina and the Rhodope mountains.

*Correspondence to: Nedelin Markov, Department of Regional Development, Faculty of $E$ conomics, Trakia University, Stara Zagora, Bulgari a,nedelin.markov@trakia-uni.bg
Up to the beginning of the 19th century Bulgarians had been engaged in gardening to satisfy the needs of the family, ie. they had been practising only home gardening. Until then, working in the garden had mostly been a woman's job. $(1,2)$

The beginning of industrial gardening in Bulgaria, according to Bulgarian authors, was set at around 1715-1720, while others claim that organized commodity gardening could be dated back as early as the middle of the 17 th century. Industrial commodity gardening, in contrast to home gardening, differed in scale, in its perfect technique, in the various worktools and the new vegetable crops that were grown. In relation to industrial vegetable production crops such as rice, aubergine, okra, alabash (from Turkey), pepper, pumpkins, tomatoes, potatoes, cauliflower (from America through Western Europe and Turkey) were introduced to gardeners. $(1,2)$

Livestock breeding, which had always been inseparable from agriculture, was the main 
livelihood of the Bulgarian people. In mountainous stock breeding, the most significant share was taken up by small livestock (sheep and goats), as well as mules, hinnies and donkeys as beasts of burden for goods and people. $(1,2)$

With the advent of industrial production in our lands, the old livelihood practices were becoming largely obsolete. Only in certain places have they survived as "living traditions", serving the local community to preserve its identity.

In the 21st century, a number of innovative initiatives have succeeded in reviving a few of the traditional practices, which could be seen as mechanisms for alternative development. For example, home-grown food and preindustrial technologies for food production, agriculture and animal husbandry are becoming increasingly popular and even underlie a number of culinary festivals - a modern form of culinary tourism. This allows for the valorization of traditions related to the production and consumption of food. This type of cultural heritage attains economic value and at the same time becomes a recognizable symbol of the respective region and therefore is given the opportunity to be a commercial product. (3)

Nowadays, researchers have agreed that the main task of sustainable development policies is to design strategies for the promotion of economic and social development in ways that avoid environmental destruction, overexploitation and pollution. Sociologists also add up to existing research with their focus on the combination of social, economic and environmental criteria for achieving sustainable rural development. The latter, as well as sustainable livelihoods in these areas, are essential for increasing food security, protecting water resources and preserving agricultural ecosystems and biodiversity. (4)

Contemporary Bulgarian research has offered an analysis of the activities of young people and families who are "living happily in the countryside, strongly inclined towards ecology and ecologically clean food; for them, rural life is entirely possible, it is even a logical and natural choice; there they grow and produce home-made food and drink from their own vineyards, vegetable gardens and orchards, wild fruits and herbs, einkorn and sunflower, and offer them at farmers' markets and on websites.' The authors conclude that the revival of such values, combined with appropriate infrastructure (which would allow villages to be seen as suburbs of larger cities), could lead to at least partial revitalization of villages and small towns. (5)

Modern "revitalization" projects in recent years share one common goal - to preserve or restore the culture of local people and reconnect them to the land for long-term individual and social health. For example, ecotourism projects stimulate cultural revival (evaluation of certain traditional practices) in combination with modern economic markets and therefore "offer an integrative approach to revitalizing and sustainable development of communities". (4)

Numerous projects in this direction are being implemented throughout the country. Consecutively implemented projects related to ideas for innovation and entrepreneurship in some Bulgarian villages lead to the following success stories: young people who move to depopulated villages in Bulgaria and implement ideas useful for the village; young people who learn organic farming and animal husbandry - to dig, weed, let animals graze on pastures, cook by using old local recipes; sustainable initiatives encouraging entrepreneurship and combining organic farming, nature conservation and ecotourism development.

The projects implemented in the last two decades combine the protection of wildlife and biodiversity; organic farming and animal husbandry and the development of sustainable tourism. The idea in most cases is to build a "closed cycle", where the money earned from the development of tourism is invested in old livelihood practices interesting for the general public, which will attract even more tourists, who will gradually cultivate a respect for the preserved natural environment and culture.

\section{Study of bioeconomy-oriented livelihood practices}

The aim of the present study is to investigate old livelihood practices in a traditionally welldeveloped tourist region, such as Bansko.

According to historical records, Bansko was established as a settlement in 15th-16th centuries, with the merging of several neighbourhoods. The first documentary evidence of Bansko could be traced to the 
Ottoman register of the Djelepkeshans (sheep breeders) from 1576 (6)

According to the official website of the municipality of Bansko, up to the 18th century the people from Bansko were mainly breeders and craftsmen who relied on the vast pastures and rich forests of the nearby mountains. During the National Revival period the settlement developed as an urban trade and craft centre. Along the river Glazne people built many mills, sawmills, rollers, fulling mills, tanneries for tanning hides, etc. Trade relations were maintained with settlements on the Aegean coast, Central and Western Europe. Caravans of carpentry, leather and iron goods headed to the Aegean Sea, the regions of Syar and Drama, and brought back cotton, fish, tobacco, olives, tanned and untanned hides. In many cities in Europe - Budapest, Vienna, Leipzig, Marseille, London - people from Bansko opened their trade shops. Many of the children of wealthy families were educated abroad. (7)

Nowadays, the sectoral structure of the economic profile of the municipality of Bansko, is dominated by the tertiary sector (service sector). Tourism is an established, leading industry in the socio-economic profile of the municipality.

Agriculture in the municipality is characterized by its extensiveness. The majority of the production is for self-sufficient purposes. Small private (family) farms prevail in the organizational production structures. Livestock farming also belongs to the private sector. Cows, goats and sheep are mainly raised. The tendency to decrease the number of farm animals, typical for the end of the first decade of the 20th century, has been overcome and in
STOYKOVA B., et al.

the last 2-3 years an increase has been observed in the number of farm animals in the municipality. (8)

Within the structure of sowing areas the largest share is taken up by the lands used for the production of cereals - wheat and rye, potatoes, maize, vegetables, and from the industrial plants - tobacco. Perennials have a small area and consist of small orchards of apples and pears. (8)

Environmental protection and the "sparing" use of natural resources on the territory are some of the main criteria of sustainable development. At the same time, biodiversity, typical for the municipality of Bansko, is considered and assessed on the one hand as an ecological capital, and on the other - as a touristic resource.

\section{METHODS}

The present study also clarifies the provision of conditions for the development of alternative forms of tourism with respect to new challenges. In particular, to what extent the revival of old livelihood practices would allow the discovery and development of new tourist niches and help attract another type of tourist flows, significantly different from traditional visitors - fans of winter and ski tourism.

The survey was conducted in the period February-March 2020 and coincided with the beginning of the epidemic situation related to COVID-19 in Bulgaria.

A wide range of respondents have taken part in the survey - including local people and outsiders who work within the municipality.

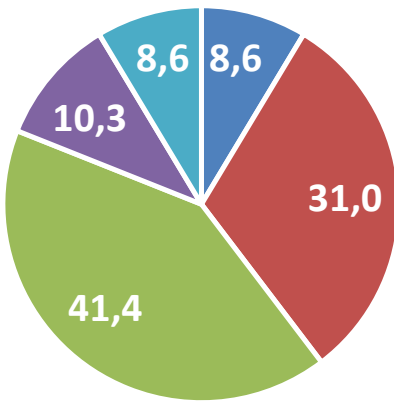

- Managerial level in the local administration

- Expert level

- Specialist in the local administration

- Employed in the agrarian sector 
A significant share $(81 \%)$ of the respondents are representatives of the local administration, and the remaining $19 \%$ are directly employed in the economy. Among the respondents, the share of specialists from the local administration departments is the largest (41.4\%), and the share of the governing bodies and those engaged in sectors outside agriculture is the lowest. (Figure 1)

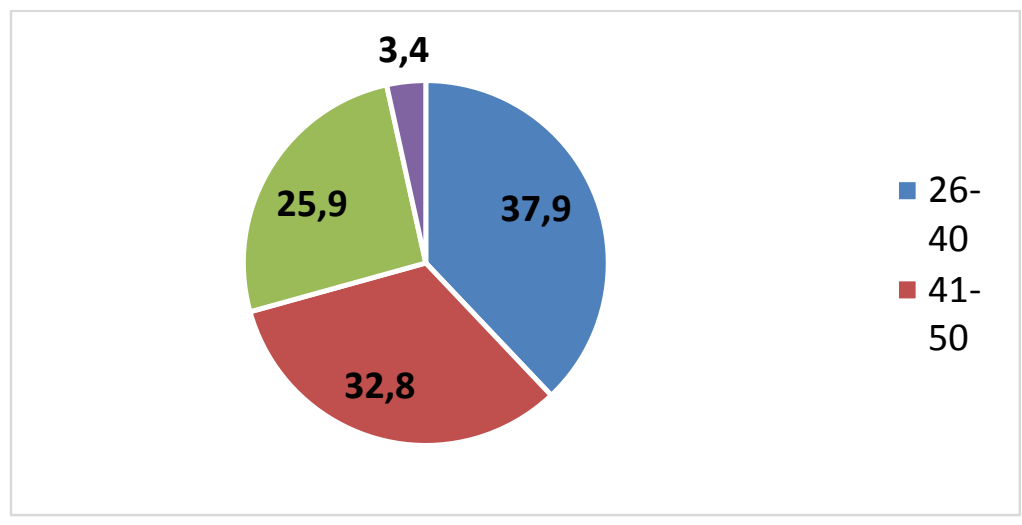

Figure 1. Share of respondents by age groups (\%)

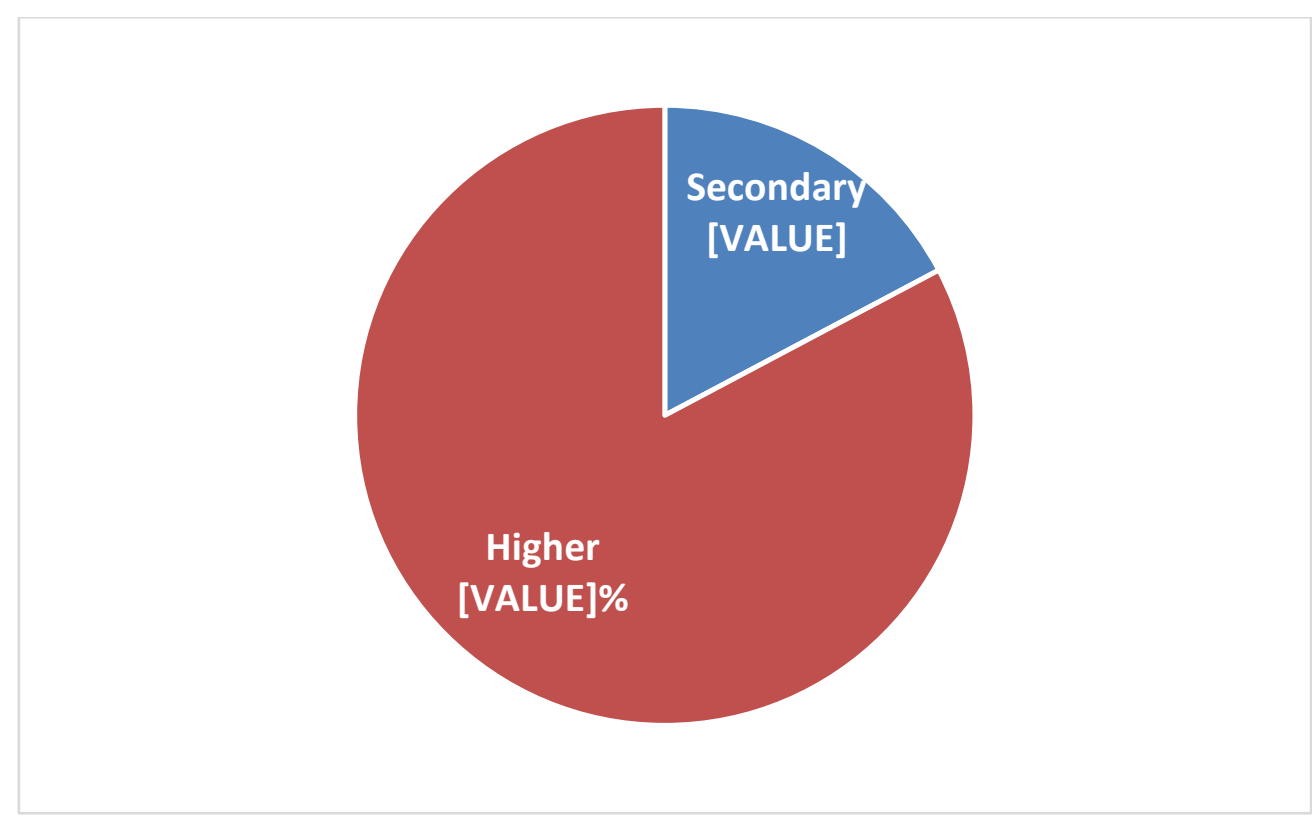

Figure 3. Share of respondents by level of education (\%)

The largest share of respondents fall into the youngest age group (up to 40 years) - $37.9 \%$, followed by those aged between 50 and 60 years - 32.8\%. (Figure 2) The share of the oldest participants (61-70 years old) is the smallest - only $3.4 \%$. By educational level, the participants in the survey have acquired predominantly higher education - almost $83 \%$. (Figure 3)

\section{RESULTS AND DISCUSSION}

Table 1 shows the shares (in\%) of the respondents by types of answers regarding the degree of use of the natural resources of the region for livelihood and the income of the population.
All participants in the survey express their opinion on the use of timber forest products for the livelihood of the population, as only $13.8 \%$ believe that it is poor, and all the remaining $86.2 \%$ are convinced that the products are exploited. However, it should be borne in mind that more than half of the respondents $(53.4 \%)$ believe that there is still untapped potential for improvement. 
Table 1. Are the natural resources available in the region used for livelihood and a source of income for the population?

\begin{tabular}{|l|c|c|c|c|c|}
\hline & Did not answer & $\begin{array}{c}\text { Not } \\
\text { used }\end{array}$ & $\begin{array}{c}\text { Poorly } \\
\text { used }\end{array}$ & $\begin{array}{c}\text { Yes, with } \\
\text { untapped } \\
\text { potential }\end{array}$ & Fully used \\
\hline Timber forest products & - & - & 13,8 & $53,4 \%$ & $32,8 \%$ \\
\hline Non-timber forest products & $8,6 \%$ & $5,2 \%$ & $46,6 \%$ & $31,0 \%$ & $8,6 \%$ \\
\hline Pastures and meadows & - & $5,2 \%$ & $17,2 \%$ & $62,1 \%$ & $15,5 \%$ \\
\hline Domestic animals & - & $5,2 \%$ & $36,2 \%$ & $50,0 \%$ & $8,6 \%$ \\
\hline Wild animals & $12,1 \%$ & $36,2 \%$ & $36,2 \%$ & $12,1 \%$ & $3,4 \%$ \\
\hline Cultivated plants & $6,9 \%$ & $10,3 \%$ & $34,5 \%$ & $41,4 \%$ & $6,9 \%$ \\
\hline Wild plants & $12,1 \%$ & $24,1 \%$ & $50 \%$ & $10,3 \%$ & $3,4 \%$ \\
\hline
\end{tabular}

In the case of non-timber forest products, some of the respondents $(8.6 \%)$ have no opinion. Here we can safely summarize that more than half of the respondents report non-use or poor use of these products. Even a significant proportion $(31 \%)$ of those who report the use of non-timber forest products declare that there is still unused potential. Only $8.6 \%$ of the respondents are convinced that this type of products is fully used.

All respondents expressed an opinion on the extent of using available pastures and meadows. The majority (77.6\%) reported that they were used, but all $62.1 \%$ determined that they were not fully used and there was still untapped potential.

Regarding domestic animals, we can report that a small part of the participants in the survey $(8.6 \%)$ believe that the resource has fully been used as an opportunity for livelihood and income of the population in the region, half see untapped potential, and a considerable part $(36.2 \%)$ think that this resource is underused.

Wildlife is a natural resource that is fairly unknown to many of the respondents $(12 \%)$. Of the remaining only $3.4 \%$ are convinced that it is fully used. The share of those who consider it as a resource with potential is also small $(12.1 \%)$. This is the natural resource that respondents have rated as very poorly used -

$72.4 \%$ have answered with either "no" or "poorly" used.
Crop farming is seen almost equally by respondents as a used and as an unused or underused resource in the region - $48.3 \%$ have answered "yes, but there is still potential" or "fully used".

In wild plants, we can report a similar response structure as in wild animals. However, it should be noted that this is the resource with the lowest share of those who believe that it is fully used or has the potential for further use $(13.7 \%)$.

The examination of the hypothesis for dependence between the position occupied by the respondents and the assessment of the degree of use of natural resources with the $\chi 2$ method shows that the position occupied by the respondents does not have a statistically significant impact (Asymp.Sig. $>\alpha=0,05$ ), which we can explain with the small number of surveys. Nevertheless, the cross tables show a definite opinion $(100 \%)$ of those working in the agricultural sector that the use of timber forest products (Figure 4) and of pastures and meadows in the area (Figure 5) are to some extent exploited for the livelihood and income of the population, but there is still untapped potential that is clearly not included as an asset for the benefit of the local population. Unlike the representatives of the agricultural sector, the answers of the respondents from the local administration and the employees outside the agricultural sector are stratified between the different levels of use. 


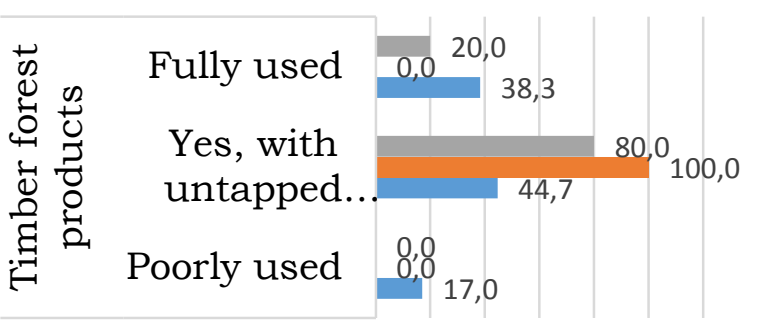

- Outside agriculture, including tourism

agriculture sector

Representatives of the local administration

0,0 20,040,060,080, $1100, \boxplus 20,0$

Figure 4. Link between the position - degree of use of timber forest products (\%)

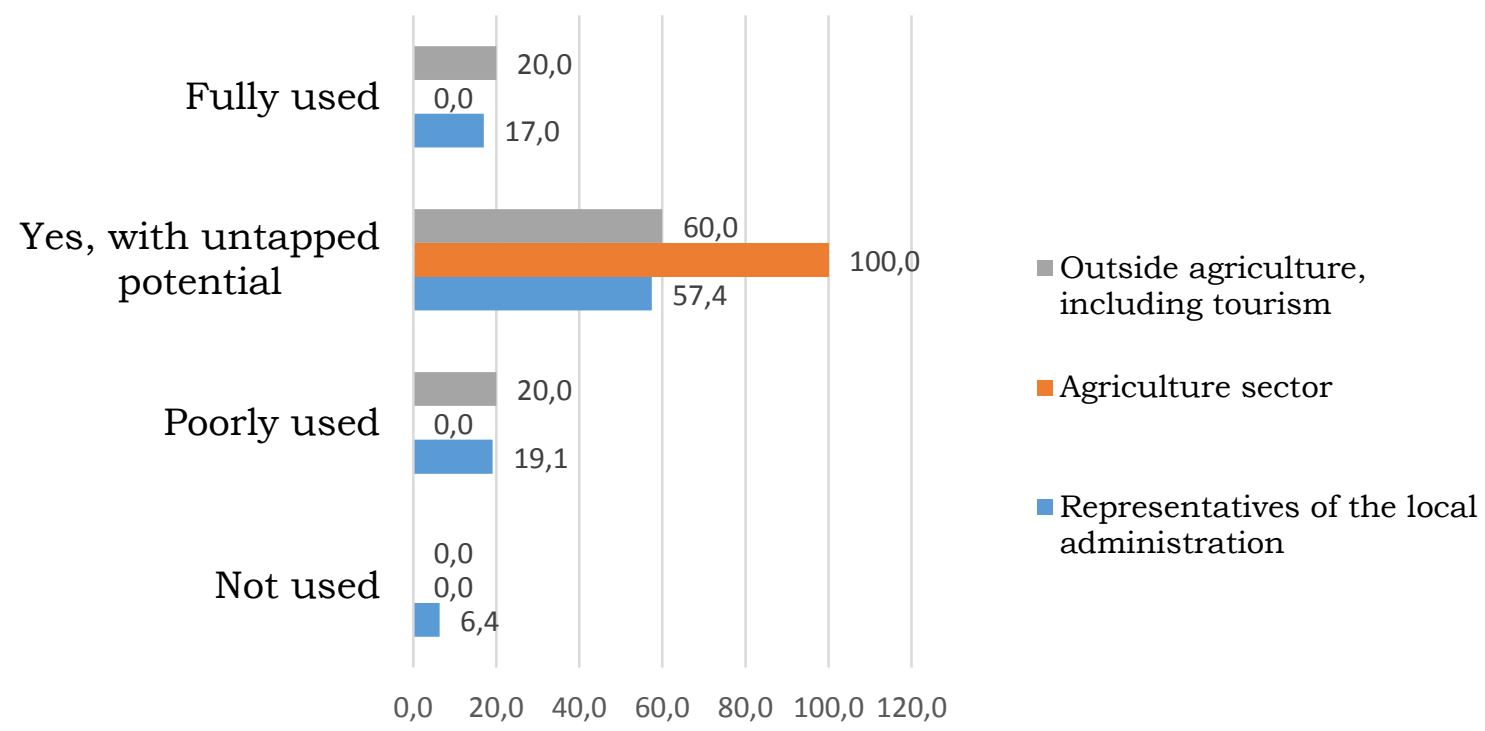

Figure 5. Link between the position-degree of use of pastures and meadows

Figure 6 shows the share of each type of answer to the question "Are the natural resources of the region linked to the development of tourism?"

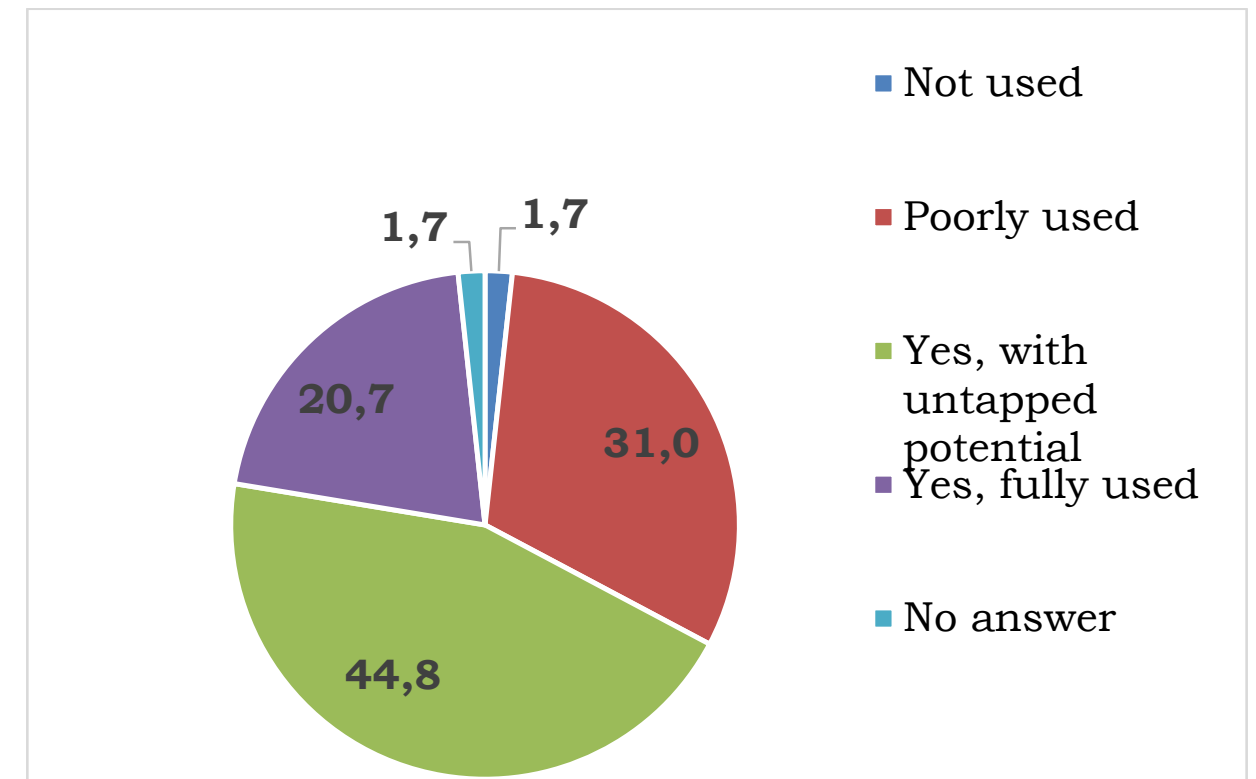

Figure 6. Degree of use of natural resources for tourism development (\% by types of answers) 
The answers shown in the figure reveal that a significant share $(65.5 \%)$ of the respondents have united around the opinion that natural resources are integrated in the development of tourism in Bansko, which is understandable in view of the developed mass tourism in the municipality which is exploiting the natural and geographical features of the region for ski tourism. However, the largest share of respondents $(44.8 \%)$ believe that there is still potential for better use of natural resources for tourism development.

Table 2 summarizes the opinions given by the respondents on the degree of maintaining traditional livelihood practices in the region.

Table 2. Are traditional livelihood practices maintained in the region?

\begin{tabular}{|l|c|c|c|c|c|}
\hline & $\begin{array}{c}\text { Did not } \\
\text { answer }\end{array}$ & Not used & Poorly used & $\begin{array}{c}\text { Yes, with } \\
\text { untapped potential }\end{array}$ & Fully used \\
\hline Agriculture & - & $1,7 \%$ & $43,1 \%$ & $51,7 \%$ & $3,4 \%$ \\
\hline Livestock farming & - & - & $41,4 \%$ & $55,2 \%$ & $3,4 \%$ \\
\hline Carpentry & - & $1,7 \%$ & $13,8 \%$ & $81.0 \%$ & $3,4 \%$ \\
\hline Ironwork & $6.9 \%$ & $19.0 \%$ & $51.7 \%$ & $19.0 \%$ & $3,4 \%$ \\
\hline Furrierv & $12.1 \%$ & $56.9 \%$ & $29.3 \%$ & $1.7 \%$ & - \\
\hline Painting & $6.9 \%$ & $20.7 \%$ & $58,6 \%$ & $10,3 \%$ & $3,4 \%$ \\
\hline Cuisine & $5.2 \%$ & $3.4 \%$ & $25.9 \%$ & $55.2 \%$ & $10.3 \%$ \\
\hline
\end{tabular}

Judging from the answers of the respondents it becomes clear that the share of those who claim that traditional livelihoods are fully used is minimal. Only in the local cuisine do we find a three times higher share of those who testify that this practice is fully active. Just over half of the respondents estimate that agriculture and livestock farming are practised in the region, but there is still potential for growth. Almost all other respondents state that these industries are underdeveloped in the region, which corresponds to the evaluation of the low use of domestic animals and crops. The lowest place in the region is furriery about $60 \%$ are convinced that it has not been exploited. Respondents rate highly the potential of carpentry (81.0\%). Ironwork and painting are poorly developed or not practiced - $70.7 \%$ and $79.3 \%$ of the respondents, respectively, but some believe that they have untapped potential.

In the cross-tabulation between the answers on the degree of use of natural resources and tourism development, on the one hand, and the degree of maintenance of traditional livelihood practices, on the other, the use of natural resources in tourism assessed as "low" coincides with the "low" practice or the underutilized potential of agriculture and animal husbandry in the region, which is a signal that the region has not yet linked the agricultural and forestry sector to the development of alternative forms of tourism. Those who claim that natural resources are linked to tourism, yet have the potential to be integrated, believe that traditional livelihoods are either underdeveloped or have underutilized potential, which again confirms that the development of alternative forms of tourism requires the preservation of traditional livelihood practices.

Along with the analysis, it is also interesting to note the answers of respondents to the open question "What is the main problem that needs to be solved in order to develop alternative forms of tourism in the municipality of Bansko related to the preservation of traditions based on natural resources and contact with domestic life and culture?". It should be mentioned that to date there is a Strategy for the Preservation of the Cultural Heritage on the Territory of Bansko Municipality 2015-2020, which sets a perspective for the transformation of the municipality of Bansko into an attractive cultural and historical tourist destination for Bulgarian and foreign tourists. (9)

Only half of the respondents express an opinion on this issue, as $15 \%$ of respondents think that there are no problems and alternative forms of tourism are well developed. The opinion of the others indicates that it is necessary to improve the environment for the development of alternative tourism in various aspects such as:

$>$ Realization of a close connection between the employees in the field of tourism and the persons, carrying out activities in the field of agriculture, animal husbandry, and timber processing; 
The development of Bansko as a world ski resort has stimulated the development of the hotel industry in the direction of all-inclusive hotels, which completely estranges tourists from the original spirit and traditions - domestic, cultural, and culinary - of the locals. In order to move in the direction of alternative tourism - cultural, rural, ecotourism, health and sports tourism, the policy and business concept of all hoteliers and restaurateurs in the municipality of Bansko must be radically changed;

$>$ Tourists visiting the resort do not have enough information about the way of life and traditions of the settlement, which requires a better program to raise their awareness and promote a wider manifestation of local traditions;

Excessive construction has led to the involvement of many foreign businessmen, who apparently undermine the traditions and originality of Bansko;

$>$ The main problem is the low income of the local people who are thus unable to develop any small or medium business related to domestic life and culture. Greater administrative relief is needed to support the start-up of small and medium-sized businesses, forms of granting funds to people who want to develop a production - dairy, cannery (for berry jam), mushroom workshops, etc.;

$>$ To provide opportunities at municipal, national and European level for designing projects for the development of the listed areas. For example, a project to expand the activities of a museum complex with the Community Center "Nikola Vaptsarov"

$>$ The municipal administration should cater to the needs of small businesses, including small family hotels, and local taverns in order to preserve, relay onto future generations the traditions and way of life of Bansko and advertise them to the tourists visiting the region. In order to preserve traditions, it is necessary to turn to our roots, namely to the generation that carries the spirit and glory of Bulgarian customs. Cultural evenings and demonstrations are among the good practices of the municipality of Bansko in this direction and they must be preserved and expanded.

\section{CONCLUSIONS}

The study shows that there are conditions for the revival of old livelihood practices in the Bansko region that contribute to a sustainable local development and modern alternative forms of tourism, applicable in the conditions of social distance.

We have found that:

$>$ The bioeconomic resources in the municipality of Bansko are poorly used or are not used to their full capacity

$>$ The aim of the local population and the municipality is to preserve their traditional culture, incl. the traditional material culture, covering livelihoods, old productions and livelihood practices, preserved culinary specialties, etc.;

$>$ There is a common interest in combining economic, social and environmental aspects, which are not mutually exclusive, but rather complement themselves;

$>$ The municipality relies on stimulated investment for the development and promotion of alternative forms of tourism, based on cultural and historical heritage and unique local natural resources;

$>$ The readiness for a continuous and timely monitoring on environmental protection in carrying out any activity on the territory of the municipality should be a priority;

The strongest impact on the preservation and stimulation of the bioeconomic potential of the municipality of Bansko and its adaptation to the new challenges would have measures aimed at:

$$
>\text { Updating basic strategic }
$$

documents of the municipality of Bansko with respect to the new realities and the need to build social and economic stereotypes after the global challenge caused by the pandemic we are experiencing;

$>$ Development of a long-term policy of the municipality of Bansko with a strong emphasis on preserving and promoting the history, way of life, culture and traditions of the settlements within the municipality. Its development and implementation should be based on the integration of all stakeholders, including in the field of agriculture, animal husbandry, logging and timber processing, tourism, etc.;

Attracting investments for the development of tourism "related to culture and traditions", which should be done through active communication between potential investors, on the one hand and local government, businesses and citizens, on the other, in order to preserve the image and cultural specificity of the town as a whole; 
Legal and regulatory relief at national and local level to create better opportunities for production and sale of traditional (homemade) food, beverages and souvenirs, unique to Bansko, to be offered in restaurants, shops and stalls;

Supporting local crafts through: providing places for their development and showing them to the public; co-financing of the craft activity through public projects; the inclusion of crafts in sightseeing tours; creating a favourable environment for small business development and supporting young start-up entrepreneurs.

$>$ Increasing the interest of the young people from the municipality through a modern presentation of the traditions and improving intergenerational continuity.

\section{ACKNOWLEDGMENT}

We wish to acknowledge the support of the National Scientific Program "Healthy Foods for Strong Bioeconomics and Quality of Life" of the Ministry of Education and Science, Bulgaria for funding our work on writing this article.

\section{REFERENCES}

1. Vakarelski, H., Ethnography of Bulgaria, Sofia, 1974;
2. Kolev, N., Bulgarian Ethnography, V. Tarnovo, 1995

3. Stoilova, E., Valorization of authentic food: festivals of traditional foods as innovative practices - In: Innovations in the village between the forgotten old and the unlearned new, Sofia, 2017

4. Stancheva, A., Ideas and practices for sustainable development of the Eastern Rhodopes following the example of the project "New Thracian Gold" - In: Innovation, development and sustainability in rural areas in Bulgaria and Europe - a collection; compiler - Sofia, 2017

5. Nedelcheva T., Innovations in the village between the forgotten old and the unlearned new - In: Innovation, development and sustainability in rural areas in Bulgaria and Europe - a collection; compiler -, Sofia, 2017

6. Encyclopedia Bulgaria, vol. 1, S., 1978, p. 212-213

7. Official site of Bansko Municipality; https://www.bansko.bg/

8. Municipal Development Plan of the Municipality of Bansko - programming period 2014-2020

9. Strategy for protection of the cultural heritage on the territory of the Municipality of Bansko 2015-2020 